\title{
Single Port Laparoscopic Cholecystectomy in a Patient with Situs Inversus Totalis: A Case Report
}

\author{
Eun Jeong Jang, M.D., Young Hoon Roh, M.D., Ph.D. \\ Department of Surgery, Dong-A University College of Medicine, Busan, Korea
}

The use and application of a laparoscopic cholecystectomy has been regarded as a first-choice treatment option for benign gallbladder disease, even if patients have situs inversus totalis. Furthermore, surgical procedures in general are becoming less invasive, because of both patient and surgeon preferences for reduced trauma and improved cosmetic outcomes attributable to minimized incisions. A 37 years old man was aware of situs inversus totalis with chronic cholecystitis. The operation was successfully performed without any specific complications. Single port laparoscopic cholecystectomy, in an experienced operator, is possible even in patients with situs inversus totalis.

Keywords: Single port laparoscopic cholecystectomy, Situs inversus totalis, Case report
Received November 28, 2018

Revised December 24, 2018

Accepted December 31, 2018

Corresponding author

Young Hoon Roh

Department of Surgery, Dong-A

University College of Medicine, 26

Daesingongwon-ro, Seo-gu, Busan

49201, Korea

Tel: +82-51-240-2619

Fax: +82-51-247-9316

E-mail: gsryh@dau.ac.kr

ORCID:

https://orcid.org/0000-0002-0165-0318

Copyright $@ 2019$ The Journal of Minimally Invasive Surgery. All rights reserved.
This is an Open Access article distributed under the terms of the Creative Commons Attribution Non-Commercial License (http // creativecommons.org/licenses/by-nc/4.0/) which permits unrestricted non-commercial use, distribution, and reproduction in any medium, provided the original work is properly cited.

\section{INTRODUCTION}

The incidence of situs inversus totalis is a rare congenital disorder in which the major visceral organs are reversed from their normal positions. ${ }^{1}$ This unusual condition is found in about 1 person in 10,000 in the general population globally.

The use and application of a laparoscopic cholecystectomy has been regarded as a first-choice treatment option for benign gallbladder disease, even if patients have situs inversus totalis. Furthermore, surgical procedures in general are becoming less invasive, because of both patient and surgeon preferences for reduced trauma and improved cosmetic outcomes attributable to minimized incisions.

Corresponding to this trend, we present in this report a case of a single port laparoscopic cholecystectomy in situs inversus totalis.

\section{CASE REPORT}

A 37 years old man was aware of situs inversus totalis visited an outpatient clinic due to the incidence of a persistent indigestion. The patient was diagnosed at the primary hospital, but was subsequently transferred to our hospital facility due to his diagnosed situs inversus totalis. The patient's preoperative diagnosis was chronic cholecystitis with gallbladder stones. The patient's chest X-ray and electrocardiogram showed signs of dextrocardia (Fig. 1). Interestingly, as noted in the abdomen pelvis CT, it was revealed that the gallbladder and liver of this patient were situated on the left, opposite to the normal anatomy, and there were small stones seen in the gallbladder (Fig. 2A, B). The patient had no other history of surgery or disease, as reviewed in the patient medical history taken.

The patient underwent general anesthesia, and was stabilized 
in a supine positioned in the operation room. The operator and assistant stood on the right side of the patient, unlike the placement of the operating room personnel in a conventional

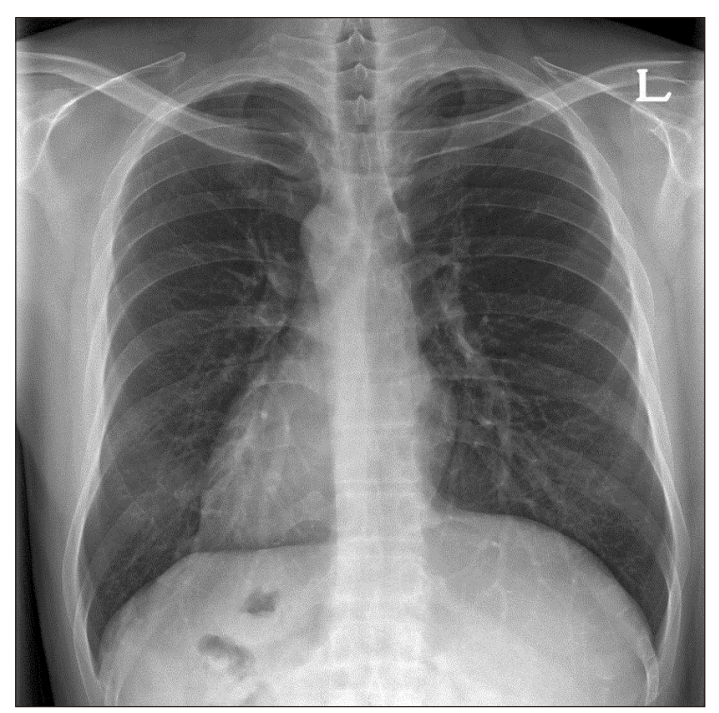

Fig. 1. Chest X-ray showed signs of dextrocardia. surgery. After an incision into the transumbilical was performed, a conventional single port was placed in the patient. The pneumoperitoneum was made by $\mathrm{CO}_{2}$ gas and patient was tilted slightly to the right at the reverse trendelenberg position. A standard $10 \mathrm{~mm}, 30$ ' angled laparoscope was used for the procedure. As shown by the $\mathrm{CT}$, all organs were reversed. The gallbladder fundus was grasped and lifted by a grasper and dissected by the application and use of a bovie hook. After the dissection of the adhesions and colon, the cystic duct and cystic artery were isolated and clipped separately by an endoclipper, and then cut by the use of a laparoscopic scissor. (Fig. 3A, B) We usually used a $10 \mathrm{~mm}$ for application of the duct and a $5 \mathrm{~mm}$ for the procedure for the artery. The remaining portion of cystic duct and cystic artery were clipped twice for each procedure requirment. Consequently, after the coagulation of the liver bed, the gallbladder specimen was taken out with the port. The total operation time took 54 minutes, and there were no special problems or complications that occurred during the surgery. There were no specific findings in the postoperative condition and laboratory findings as reviewed in this case. The patient was discharged two days after the operation as is normally the case for this operation. The histologic exami-
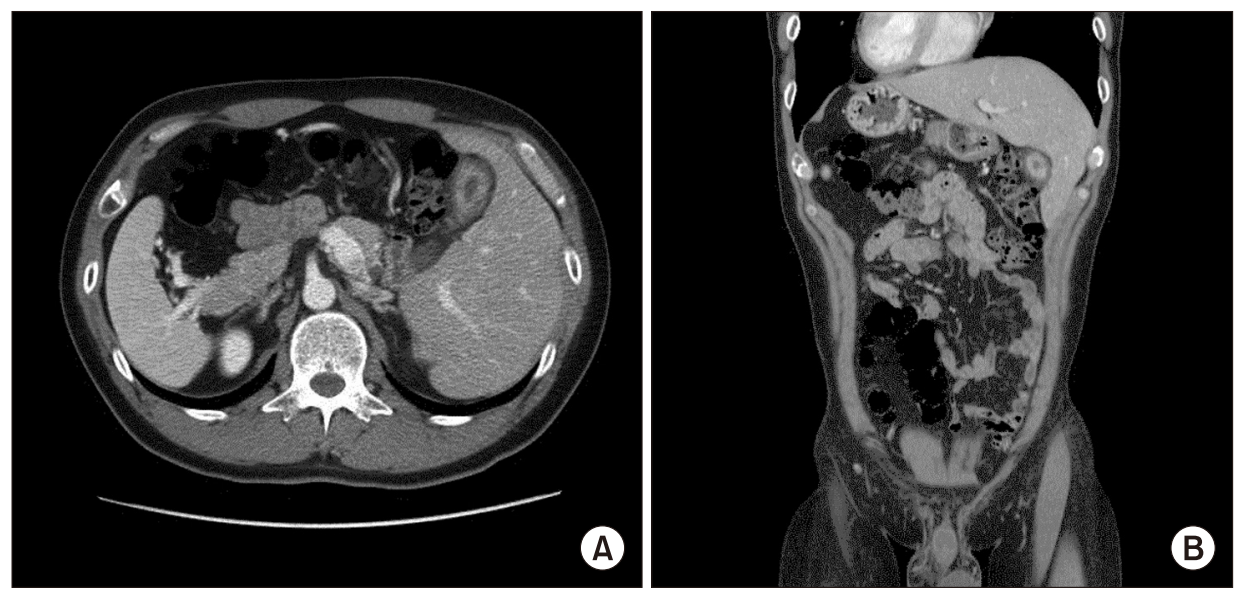

Fig. 2. (A, B) In abdomen pelvis CT, Gallbladder and liver were on the left, opposite to the normal anatomy, and there were small stones seen in the gallbladder.
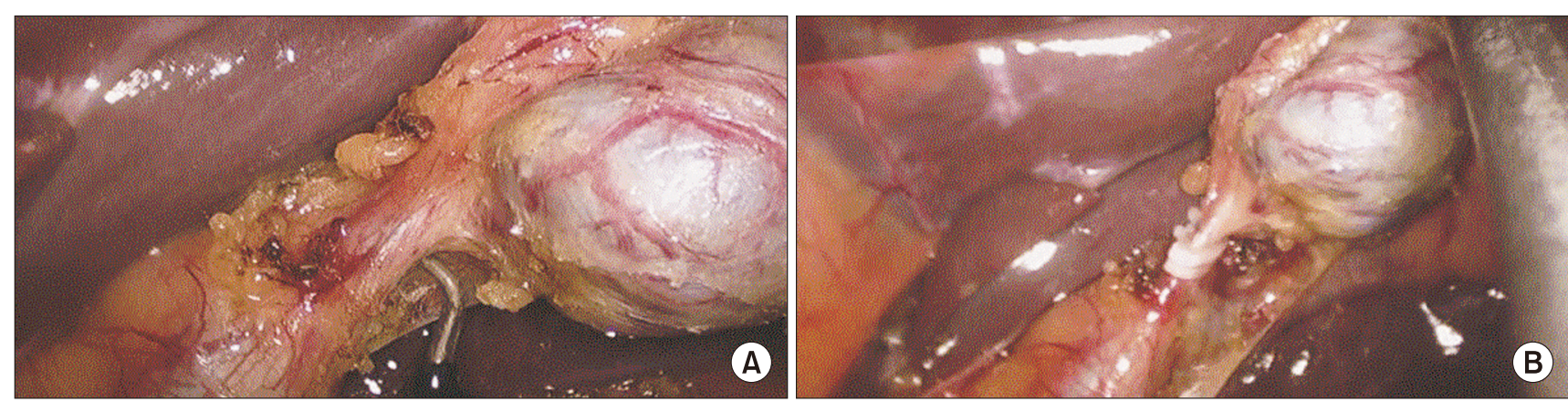

Fig. 3. (A, B) In the Laparoscopic view of Calot's triangle, Gallbladder and liver were on the left similar to the abdomen pelvis CT (A), Cystic duct and cystic artery were isolated and double clipped separately by Hem-o-Lok (B). 
nation confirmed that the patient had adenomyomatosis. Six months after operation, there were no problems as detected in the follow-up ultrasonography examination.

\section{DISCUSSION}

Situs inversus totalis is a rare disorder with low prevalence in populations $(0.01 \%)$. Frequently, it can be associated with many other anatomical variations including biliary tract and vascular anomalies., ${ }^{2,3}$ There is no evidence to suggest that gallstones are more common in people with this condition, however if this condition were unknown at the time of presentation, it could result in a delay in the diagnosis of cholelithiasis. ${ }^{4}$ In 1991, Campos and Sipes were the first to report a successful laparoscopic cholecystectomy in a patient with situs inversus totalis. ${ }^{5}$ Since then, many other cases have been published in a review of literature on the topic. In response to the patients' demands for less pain and better cosmetic results, five cases of single port laparoscopic cholecystectomy in situs inversus totalis patients have been published currently., ${ }^{4,6-8}$

Laparoscopic cholecystectomy is the most conventional procedure applicable in all cases, but there is a disadvantage in the use with situs inversus totalis patients, as the operation is difficult for right -handed surgeons to handle instruments and mirror images. There are many ways to overcome these limitations, but there is no established method yet. ${ }^{9}$ In addition, recent studies have shown that single port laparoscopic cholecystectomy is not considered to effect inferior post op outcomes, as compared to conventional applications. ${ }^{10}$ Also, since our operator is an experienced surgeon who had performed more than 1,000 cases of single port laparoscopic cholecystectomy, we tried single port laparoscopic cholecystectomy in patients with situs inversus totalis.

From our experience, in the case of single port laparoscopic cholecystectomy in situs inversus totalis, a skilled operator on the single port itself can proceed with the surgery without significant difference from the utilization of conventional laparoscopic cholecystectomy.

\section{CONCLUSION}

This case shows that single port laparoscopic cholecystectomy, in an experienced operator, is possible even in patients with situs inversus totalis.

\section{ETHICAL STATEMENT}

The study was approved by the Institutional Review Board (IRB) of Dong-A University Hospital.

Case reports are exempted from ethical approval. Because all data were collected from clinical records and imaging systems.

\section{ORCID}

Eun Jeong Jang, https://orcid.org/0000-0002-8993-7769

Young Hoon Roh, https://orcid.org/0000-0002-0165-0318

\section{AUTHORS' CONTRIBUTIONS}

Conceptualization: YHR. Formal analysis: YHR. Methodology: YHR. Writing-original draft: EJJ. Writing-review and editing: YHR.

\section{CONFLICT OF INTEREST}

None.

\section{FUNDING}

None.

\section{ACKNOWLEDGMENTS}

None.

\section{REFERENCES}

1) Bogarapu CB, Savalam RKB, Chinthagada J, Kattupalli SC. Laparoscopic cholecystectomy in a patient with situs inversus totalis: a case report. Int J Res Med Sci 2015;3:805-807.

2) Nursal TZ, Baykal A, Iret D, Aran O. Laparoscopic cholecystectomy in a patient with situs inversus totalis. J Laparoendosc Adv Surg Tech A 2001;11:239-241.

3) Kamitani S, Tsutamoto Y, Hanasawa K, Tani T. Laparoscopic cholecystectomy in situs inversus totalis with "inferior" cystic artery: a case report. World J Gastroenterol 2005;11:5232-5234.

4) de Campos Martins MVD, Pantaleão Falcão JL, Skinovsky J, de Faria GMSS. Single-port cholecystectomy in a patient with situs inversus totalis presenting with cholelithiasis: a case report. J Med Case Rep 2012;6:96.

5) Martins M, Coelho D, Coelho J, Rios M. Initial experience with natural orifices transluminal endoscopic surgery. Rev Brás VídeoSur 2006;4:75-77.

6) Ozsoy M, Haskaraca MF, Terzioglu A. Single incision laparoscopic cholecystectomy (SILS) for a patient with situs inversus totalis. BMJ Case Rep 2011. DOI:10.1136/bcr.08.2011.4581.

7) Bozkurt S, Coskun H, Atak T, Kadioglu H. Single incision laparoscopic cholecystectomy in situs inversus totalis. J Surg Tech Case Rep 2012;4:129-131. 
8) Deguchi Y, Mitamura K, Omotaka S, et al. Single-incision cholecystectomy in a patient with situs inversus totalis presenting with cholelithiasis: a case report. Asian J Endosc Surg 2015;8:347-349.

9) Alam A, Santra A. Laparoscopic cholecystectomy in a case of situs inversus totalis: a review of technical challenges and adaptations.
Ann Hepatobiliary Pancreat Surg 2017;21:84-87.

10) Partelli S, Barugola G, Sartori A, Crippa S, Falconi M, Ruffo G. Single-incision laparoscopic cholecystectomy versus traditional laparoscopic cholecystectomy performed by a single surgeon: findings of a randomized trial. Surg Today 2016;46:313-318. 